\title{
Prevalence and Impact of Treatment-Resistant Depression in Latin America: a Prospective, Observational Study
}

\author{
Bernardo Soares ${ }^{1} \cdot$ Gabriela Kanevsky $^{2} \cdot$ Chei Tung Teng $^{3} \cdot$ Rodrigo Pérez-Esparza $^{4}$. \\ Gerardo Garcia Bonetto ${ }^{5}$. Acioly L. T. Lacerda ${ }^{6}$. Erasmo Saucedo Uribe ${ }^{7}$. \\ Rodrigo Cordoba ${ }^{8}$. Christian Lupo ${ }^{9}$. Aline Medeiros Samora ${ }^{10} \cdot$ Patricia Cabrera $^{11}$ (D)
}

Accepted: 30 May 2021 / Published online: 31 August 2021

(c) The Author(s) 2021

\begin{abstract}
Approximately one-third of patients with major depressive disorder (MDD) have treatmentresistant depression (TRD). The TRAL study will evaluate the prevalence and impact of TRD among patients with MDD in four Latin American countries. In this multicenter, prospective, observational study, patients with MDD were recruited from 33 reference sites in Mexico, Colombia, Brazil, and Argentina. Patients were assessed for TRD, defined as failure to respond to $\geq 2$ antidepressant medications of adequate dose and duration. Demographics, previous/current treatments, depressive symptoms, functioning, healthcare resource utilization, and work impairment were also collected and evaluated using descriptive statistics, chi-square test, Fisher exact test, $t$-test for independent samples, or the Mann-Whitney nonparametric test, as appropriate. 1475 patients with MDD were included in the analysis (mean age, 45.6 years; $78 \%$ women); $89 \%$ were receiving relevant psychiatric treatment. 429 patients met criteria for TRD, and a numerically higher proportion of patients with TRD was present in public versus private sites of care (31\% vs 27\%). The mean MontgomeryAsberg Depression Rating Scale score was 25.0 among all MDD patients and was significantly higher for patients with TRD versus non-TRD (29.4 vs $23.3 ; P<0.0001)$. Patients with TRD, versus those with non-TRD, were significantly more likely to be older, have a longer disease duration, have more comorbidities, be symptomatic, have a higher median number of psychiatric consultations, and report greater work impairment. Patients with TRD have a disproportionate burden of disease compared to those with non-TRD. Appropriate treatment for TRD is a substantial unmet need in Latin America. https://www.ClinicalTrials.gov identifier NCT03207282, 07/02/2017.
\end{abstract}

Keywords Treatment-resistant depressive disorder - Major depressive disorder . Prevalence $\cdot$ Health care utilization $\cdot$ Latin America

Bernardo Soares is currently affiliated with Sanofi - Brazil.

Rodrigo Pérez-Esparza has been included under posthumous authorship.

Patricia Cabrera is currently affiliated with Janssen Global Services, Inc, Titusville, NJ.

Patricia Cabrera

pcabrer1@ITS.JNJ.com

Extended author information available on the last page of the article 


\section{Background}

Major depressive disorder (MDD) is a worldwide health concern, affecting over 300 million people. MDD has a significant impact on core aspects of life, including sleeping, eating, intellect, and self-worth [1,2]. In a recent systematic review and meta-analysis, $27.0 \%$ of outpatients had depression or showed depressive symptoms [3]. According to the World Health Organization, MDD is the largest contributor to disability globally [1]. The impact of MDD on disability is due, in part, to a substantial proportion of patients with MDD who do not respond to current treatments despite available antidepressants and augmentation strategies [4].

An estimated one-third of patients with MDD have treatment-resistant depression (TRD), usually defined as a failure to respond to $\geq 2$ antidepressant medications of adequate dose and duration [5-7]. A great deal of MDD-related disease burden can be ascribed to TRD. Compared to patients with MDD who are not resistant to treatment, those with TRD have more comorbidities, poorer health-related quality of life, greater risk of suicide, greater direct and indirect healthcare resource utilization, and greater costs [8-14]. Patients with TRD currently have limited approved therapeutic options. For example, in the United States, only fluoxetine/olanzapine was approved for the treatment of TRD until March 2019, when intranasal esketamine was also approved [15-17].

Most studies of depression in Latin America have focused broadly on MDD. One study of MDD involving 1835 patients from Argentina, Brazil, Chile, Colombia, and Mexico hospital emergency departments showed an MDD prevalence ranging from $23.0 \%$ to $35.0 \%$ [18]. Compared to patients without MDD, those with MDD were more likely to be middle aged, be women, be smokers, have a lower socioeconomic level, and have a diagnosis of asthma or arthritis/rheumatism. Multivariate analysis identified an independent association between MDD and lower education level, smoking, self-reported anxiety, chronic fatigue, and back problems. Additionally, two Latin American, multicenter, observational studies found that the presence of somatic symptoms in patients with MDD was associated with higher depression severity and resulted in higher pain scores and a deleterious effect on quality of life [19]. The São Paulo Ageing \& Health Study found that older Brazilian adults ( $\geq 65$ years of age) with MDD had higher rates than nondepressed older adults of both hospitalization and use of outpatient services, underlining the healthcare burden of MDD in Latin America [20].

Although depression has been systematically studied in Latin America, TRD has not. The TRAL (Treatment Resistant Depression in America Latina) study is the first international, multicenter, prospective, observational, noninterventional study of TRD in four Latin American countries: Mexico, Colombia, Brazil, and Argentina. In this study, the diagnosis of MDD was determined by semi-structured interview to ensure a uniform study population, and patients found to have TRD will be followed for an additional year to gain insight into changes in responses over time. Reported here are results from the baseline cross-sectional analysis of TRAL.

\section{Materials and Methods}

\section{Objectives}

The primary objectives of this study are to 1) estimate the prevalence of TRD among patients with MDD being treated in psychiatric reference sites (clinic, ambulatory, hospital, day-hospital) in Mexico, Colombia, Brazil, and Argentina and 2) evaluate depression-related healthcare resource 
utilization among patients with TRD. As a secondary outcome, the study aims to describe the characteristics of patients with MDD, including comorbidities, treatment standards, severity of symptoms, utilization of medical resources, and level of disability.

\section{Study Design and Population}

The TRAL study is an international, multicenter, prospective, observational, noninterventional study consisting of two phases:

1. Phase 1 (cross-sectional): patients with MDD were assessed to determine demographic data, previous and current treatments, depressive symptoms, suicidality, quality of life, functioning/disability, and general life. TRD prevalence was estimated, and patients with this diagnosis were included in Phase 2.

2. Phase 2 (cohort): 1-year follow up of a subset of patients with TRD.

Key inclusion criteria for Phase 1 were women and men; age $\geq 18$ years; an MDD diagnosis according to the Diagnostic and Statistical Manual of Mental Disorders, 5th Edition and confirmed by the MINI International Neuropsychiatric Interview, 7.0.2 version (MINI); treatment or lack of treatment for a new or continued episode of depression at the time of enrollment; and the capability to complete the corresponding assessments in the study. The diagnosis of TRD was based on the following criteria: adequate follow-up and treatment with $\geq 2$ antidepressants and lack of a complete response to treatment (based on the Montgomery-Asberg Depression Rating Scale [MADRS]); each investigator diagnosed TRD according to their discretion based on these criteria. Key exclusion criteria were a diagnosis of psychosis, schizophrenia, bipolar disorder, schizoaffective disorder, or dementia; substance dependence that was considered serious by the investigator; and current participation in another clinical study. Patients with a clinical diagnosis of depression, assessed by a single healthcare provider, were assessed for inclusion criteria in Phase 1. Data sources included patients' medical records, as well as questionnaires, scales, and assessments completed by patients and investigators.

\section{Outcome Measures}

The primary outcomes of the TRAL study were 1) the prevalence of TRD among MDD patients being treated in a psychiatric reference site and 2) depression-related healthcare resource utilization in TRD patients. Secondary outcomes included 1) TRD patients' characteristics, including comorbid conditions, treatment patterns, severity of symptoms, and level of disability; 2) suicidality risk (ideation and attempts) in TRD patients; 3 ) total healthcare costs and depression-related healthcare costs in TRD patients; and 4) indirect costs associated with work productivity loss, daily functioning loss, quality of life, and caregiver burden. This interim analysis focuses on primary outcome 1 and secondary outcome 1 .

\section{Analyses}

Data collected included sociodemographic and clinical characteristics, clinical response (measured by MADRS total score), current disease status, MINI results, previous and current medication use, healthcare resource utilization, and work productivity (as measured 
by the Work Productivity and Activity Impairment Questionnaire: Depression [WPAI:D]). Prevalence of TRD was evaluated in the overall population and by country among patients with MDD (primary endpoint) and type of site of care (private or public). The proportion of untreated patients with MDD was also evaluated. Treated patients were defined as having received $\geq 1$ current relevant psychiatric therapy by the first study visit. Other variables, including scales and questionnaires, were assessed among all patients with MDD, the subset of patients without TRD (non-TRD), and the subset of patients with TRD.

Descriptive statistics were used to evaluate sociodemographic and clinical variables in patients with MDD and by group (non-TRD and TRD) during Phase 1. For quantitative variables, mean, standard deviation (SD), median, and range were calculated. For qualitative variables, frequencies and percentages were calculated. $95 \%$ confidence intervals were also presented for prevalence.

Comparisons between TRD and non-TRD regarding categorical variables were performed using the chi-square test (CS) or Fisher exact test and through the $t$-test for independent samples (TT) or the Mann-Whitney nonparametric test (MW), according to the assumption validations of the statistical tests for quantitative variables, as identified in the tables. Comparison between countries regarding the proportion of treated patients was performed through the CS test. There was no imputation of missing data, except for incomplete dates. All statistical tests were two-tailed considering a significance level of 5\%. Statistical analysis was conducted through the software SAS ${ }^{\circledR}$ (version 9.4; SAS Institute Inc, Cary, NC, USA).

\section{Results}

\section{Study Population and TRD Prevalence}

A total of 1544 patients were screened, of whom 1475 (96\%) were included in the analysis dataset for Phase 1. Patients were from 33 centers in four countries: Mexico $(n=697 ; 47 \%$ of all patients), Colombia $(n=162 ; 11 \%)$, Brazil $(n=396 ; 27 \%)$, and Argentina $(n=220$; $15 \%)$. Among these patients with MDD, $89 \%$ were treated and $11 \%$ were untreated (Table 1). By country, the proportion of untreated patients ranged from $2 \%$ (Argentina) to $14 \%$ (Mexico), and differences between countries were statistically significant.

The prevalence of TRD in Latin American sites among patients with MDD was 29\% (429 patients; 95\% confidence interval: 27\%-31\%; Fig. 1). Among treated patients with MDD, the prevalence of TRD was $32 \%$ (95\% confidence interval: $29 \%-34 \%$ ). By country, the lowest prevalence of TRD was observed in Mexico (21\%) and the highest was observed

Table 1 Prevalence of treated and untreated MDD among patients, overall and by country ${ }^{\mathrm{a}}$

\begin{tabular}{lllllll}
\hline & $\begin{array}{l}\text { Total MDD population } \\
(N=1475)\end{array}$ & $\begin{array}{l}\text { Mexico } \\
(n=697)\end{array}$ & $\begin{array}{l}\text { Colombia } \\
(n=162)\end{array}$ & $\begin{array}{l}\text { Brazil } \\
(n=396)\end{array}$ & $\begin{array}{l}\text { Argentina } \\
(n=220)\end{array}$ & $P$ value \\
\hline Treated & $1318(89.4 \%)$ & $601(86.2 \%)$ & $140(86.4 \%)$ & $362(91.4 \%)$ & $215(97.7 \%)$ & \\
Untreated & $157(10.6 \%)$ & $96(13.8 \%)$ & $22(13.6 \%)$ & $34(8.6 \%)$ & $5(2.3 \%)$ & $<0.0001(\mathrm{CS})$ \\
\hline
\end{tabular}

$M D D$ major depressive disorder, $C S$ chi-square test

aPatients were classified as treated if they had a "yes" answer for the question "Is the patient receiving psychiatric therapy?" at Visit 1 


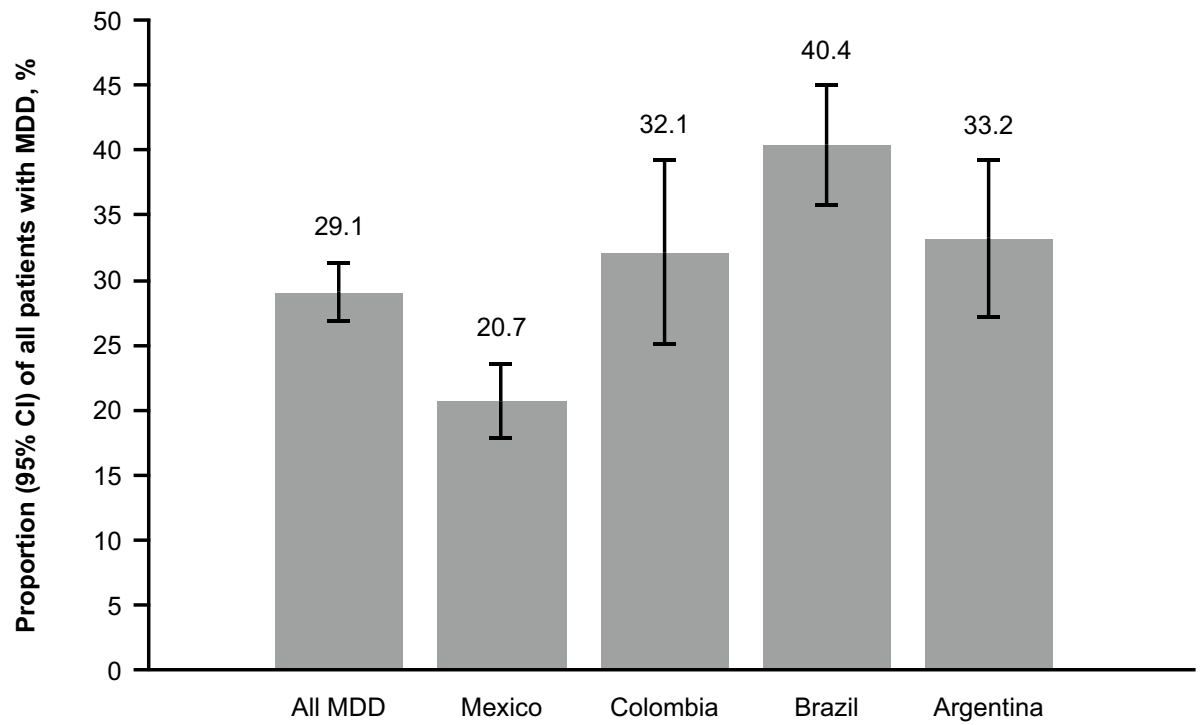

Fig. 1 Prevalence of TRD among patients with MDD, overall and by country. TRD treatment-resistant depression, $M D D$ major depressive disorder, $C I$ confidence interval

in Brazil (40\%); prevalences in Colombia and Argentina were 32\% and 33\%, respectively. Overall, the prevalence of TRD was numerically higher in public sites of care (31\%) than in private sites of care (27\%; Table 2), and varied by more specific categorizations (eg, $19 \%$ among patients in public psychiatric clinical sites vs $60 \%$ among patients at general hospitals; Online Resource 2).

\section{Sociodemographic and Clinical Characteristics}

Among all patients with MDD, the mean age was 45.6 years, $78 \%$ were female, $44 \%$ $\operatorname{had} \geq 13$ years of formal education, the mean age at diagnosis was 37.9 years, the median

Table 2 TRD prevalence among patients with MDD by type of care site, overall and by country ${ }^{\mathrm{a}}$

\begin{tabular}{llllll}
\hline & $\begin{array}{l}\text { Total MDD } \\
\text { population } \\
(N=1475)\end{array}$ & $\begin{array}{l}\text { Mexico } \\
(n=697)\end{array}$ & $\begin{array}{l}\text { Colombia } \\
(n=162)\end{array}$ & $\begin{array}{l}\text { Brazil } \\
(n=396)\end{array}$ & $\begin{array}{l}\text { Argentina } \\
(n=220)\end{array}$ \\
\hline $\begin{array}{l}\text { Private sites of } \\
\text { care }\end{array}$ & $202(27.1 \%)$ & $78(22.3 \%)$ & $41(35.3 \%)$ & $10(16.7 \%)$ & $73(33.2 \%)$ \\
$\begin{array}{c}\text { Public sites of } \\
\text { care }\end{array}$ & $\begin{array}{l}{[23.9 \%-30.3 \%]} \\
{[27(31.1 \%)}\end{array}$ & $66.9 \%-26.6 \%]$ & {$[26.2 \%-44.0 \%]$} & {$[7.2 \%-26.1 \%]$} & {$[27.0 \%-39.4 \%]$} \\
\hline
\end{tabular}

TRD treatment-resistant depression, $M D D$ major depressive disorder, $C I$ confidence interval

${ }^{a}$ Data are reported as prevalence $(95 \% \mathrm{CI})$. Prevalence is based on the total numbers of patients from private or public sites of care, as appropriate. These values for private and public sites of care, respectively, were: 746 and 729 (total MDD population), 350 and 347 (Mexico), 116 and 46 (Colombia), 60 and 336 (Brazil), and 220 (Argentina [private sites of care only]) 
Table 3 Sociodemographic and clinical characteristics at baseline

\begin{tabular}{|c|c|c|c|c|}
\hline & $\begin{array}{l}\text { All MDD } \\
(N=1475)\end{array}$ & $\begin{array}{l}\text { Non-TRD } \\
(n=1046)\end{array}$ & $\begin{array}{l}\text { TRD } \\
(n=429)\end{array}$ & $P$ value $^{\mathrm{a}}$ \\
\hline \multicolumn{5}{|l|}{ Age, years } \\
\hline Mean & 45.6 & 44.4 & 48.5 & $<0.0001(\mathrm{MW})$ \\
\hline Standard deviation & 15.22 & 15.85 & 13.13 & \\
\hline \multicolumn{5}{|l|}{ Gender, $n(\%)$} \\
\hline Female & $1150(78.0 \%)$ & $803(76.8 \%)$ & $347(80.9 \%)$ & $0.0832(\mathrm{CS})$ \\
\hline Male & $325(22.0 \%)$ & $243(23.2 \%)$ & $82(19.1 \%)$ & \\
\hline Marital status, $n(\%)^{\mathrm{b}}$ & 1459 & 1036 & 423 & \\
\hline Single & $538(36.9 \%)$ & $392(37.8 \%)$ & $146(34.5 \%)$ & $0.0035(\mathrm{CS})$ \\
\hline Married/consensual union & $665(45.6 \%)$ & $486(46.9 \%)$ & $179(42.3 \%)$ & \\
\hline Divorced/separated & $176(12.1 \%)$ & $106(10.2 \%)$ & $70(16.5 \%)$ & \\
\hline Widower & $80(5.5 \%)$ & $52(5.0 \%)$ & $28(6.6 \%)$ & \\
\hline Years of formal education, $n(\%)^{\mathrm{b}}$ & 1357 & 965 & 392 & \\
\hline 0 & $4(0.3 \%)$ & $3(0.3 \%)$ & $1(0.3 \%)$ & $0.8170(\mathrm{CS})$ \\
\hline $1-4$ & $51(3.8 \%)$ & $35(3.6 \%)$ & $16(4.1 \%)$ & \\
\hline $5-9$ & $309(22.8 \%)$ & $212(22.0 \%)$ & $97(24.7 \%)$ & \\
\hline $10-12$ & $391(28.8 \%)$ & $283(29.3 \%)$ & $108(27.6 \%)$ & \\
\hline$\geq 13$ & $602(44.4 \%)$ & $432(44.8 \%)$ & $170(43.4 \%)$ & \\
\hline Age at diagnosis, years ${ }^{\mathrm{b}}$ & 1434 & 1020 & 414 & \\
\hline Mean & 37.9 & 38.2 & 37.3 & $0.5973(\mathrm{MW})$ \\
\hline Standard deviation & 15.06 & 15.46 & 14.02 & \\
\hline MDD disease duration, years ${ }^{\mathrm{b}}$ & 1434 & 1020 & 414 & \\
\hline Median & 3.6 & 1.9 & 8.0 & $<0.0001(\mathrm{MW})$ \\
\hline Minimum & 0.0 & 0.0 & 0.0 & \\
\hline Maximum & 69.2 & 46.9 & 69.2 & \\
\hline \multicolumn{5}{|l|}{$\begin{array}{l}\text { Number of hospitalizations for MDD in the last } \\
\text { year }\end{array}$} \\
\hline Median & 1.0 & 1.0 & 1.0 & $0.5888(\mathrm{MW})$ \\
\hline Minimum & 1.0 & 1.0 & 1.0 & \\
\hline Maximum & 5.0 & 5.0 & 4.0 & \\
\hline Number of days hospitalized in the last year ${ }^{\mathrm{b}}$ & 80 & 56 & 24 & \\
\hline Median & 14.0 & 14.0 & 11.5 & $0.7685(\mathrm{MW})$ \\
\hline Minimum & 1.0 & 1.0 & 1.0 & \\
\hline Maximum & 157.0 & 157.0 & 96.0 & \\
\hline \multicolumn{5}{|l|}{ Comorbidities, $n(\%)$} \\
\hline Disease other than MDD & $741(50.2 \%)$ & $468(44.7 \%)$ & $273(63.6 \%)$ & $<0.0001(\mathrm{CS})$ \\
\hline Respiratory $^{\mathrm{c}}$ & $90(12.2 \%)$ & $55(11.8 \%)$ & $35(12.8 \%)$ & $0.6753(\mathrm{CS})$ \\
\hline Cardiovascular $^{\mathrm{c}}$ & $318(43.0 \%)$ & $179(38.3 \%)$ & $139(50.9 \%)$ & $0.0008(\mathrm{CS})$ \\
\hline Digestive $^{c}$ & $168(22.7 \%)$ & $95(20.3 \%)$ & $73(26.7 \%)$ & $0.0450(\mathrm{CS})$ \\
\hline Endocrine & $308(41.6 \%)$ & $177(37.8 \%)$ & $131(48.0 \%)$ & 0.0068 (CS) \\
\hline Genitourinary $^{\mathrm{c}}$ & $108(14.6 \%)$ & $55(11.8 \%)$ & $53(19.4 \%)$ & $0.0045(\mathrm{CS})$ \\
\hline Hematopoietic $^{c}$ & $41(5.5 \%)$ & $23(4.9 \%)$ & $18(6.6 \%)$ & $0.3385(\mathrm{CS})$ \\
\hline Musculoskeletal $^{\mathrm{c}}$ & $174(23.5 \%)$ & $98(21.0 \%)$ & $76(27.8 \%)$ & $0.0339(\mathrm{CS})$ \\
\hline Neurological $^{c}$ & $179(24.2 \%)$ & $113(24.2 \%)$ & $66(24.2 \%)$ & $0.9948(\mathrm{CS})$ \\
\hline Sense organs ${ }^{c}$ & $63(8.5 \%)$ & $41(8.8 \%)$ & $22(8.1 \%)$ & 0.7346 (CS) \\
\hline Skin and appendices ${ }^{c}$ & $57(7.7 \%)$ & $38(8.1 \%)$ & $19(7.0 \%)$ & $0.5622(\mathrm{CS})$ \\
\hline
\end{tabular}

$M D D$ major depressive disorder, $T R D$ treatment-resistant depression, $M W$ Mann-Whitney nonparametric test, $C S$ chi-square test

${ }^{\mathrm{a}}$ TRD versus non-TRD

${ }^{\mathrm{b}}$ Some patients had missing data. Numbers of patients with available data in each population are specified in this row

${ }^{\mathrm{c}}$ One patient (with non-TRD) was missing data 
duration of MDD was 3.6 years, and 50\% had a disease other than MDD (Table 3). Compared to patients with non-TRD, those with TRD were significantly older, were more likely to be divorced/separated, had a longer MDD disease duration, and were more likely to have comorbidities. No significant differences were observed between the non-TRD and TRD groups in regard to age at diagnosis, years of formal education, and number of hospitalizations for MDD in the past year.

\section{Characterization of Patients' MDD}

The mean total MADRS score was 25.0 among all patients with MDD and was significantly lower for patients with non-TRD (23.3) versus those with TRD $(29.4 ; P<0.0001$ [MW]; Fig. 2a). Significantly more patients with non-TRD (82\%) had no symptoms or mild or moderate depression (MADRS total score 0-34) compared to patients with TRD (74\%; $P=0.0016[\mathrm{CS}])$. Among patients with TRD, $61 \%$ were classified as having moderate depression and $26 \%$ as having severe depression (Fig. 2b).

According to the current disease status questionnaire, a significantly higher proportion of patients with TRD $(99.8 \%)$ were symptomatic compared to patients with nonTRD (90.3\%; Online Resource 3). Significant differences between these groups were also observed for specific mental, emotional, or physical items (eg, persistent sad, anxious, or "empty" feelings; difficulty concentrating, remembering details, and making decisions). Notably, 39\% of patients with TRD reported thoughts of suicide or suicide attempts (vs $25 \%$ of patients with non-TRD; $P<0.0001$ ).

Based on MINI results, compared to patients with non-TRD, those with TRD were significantly more likely to have a current (91\% vs $97 \%$ ) or recurrent (43\% vs $73 \%$ ) major depressive episode, current suicidality $(20 \%$ vs $35 \%)$ or a lifetime suicide attempt $(14 \%$ vs $28 \%$; all $P<0.0001)$, as well as generalized anxiety disorder (18\% vs $26 \% ; P=0.0002$; Table 4).

\section{MDD Treatment Schemes}

Among all patients with MDD, 63\% had received previous psychiatric medication (nonTRD: 49\%; TRD: 97\%). Current therapy use among all patients with MDD was as follows: $89 \%$ of patients were on treatment with medications used for MDD (non-TRD: $86 \%$; TRD: $97 \%$ ) and $37 \%$ with other relevant therapy (ie, nonpsychiatric therapies prescribed for conditions other than MDD; non-TRD: 33\%; TRD: 48\%; Table 5). Eleven of the 429 patients with TRD were not currently being treated but were clinically considered to have TRD based on having MDD and a history of antidepressant failure. For these patients, the median (range) duration of time since the last psychiatric medication was $9.0(0.0-208.0)$ months.

The class of antidepressants most frequently reported as current medication was selective serotonin reuptake inhibitors (SSRIs; 62\% of all patients), followed by serotonin and noradrenaline reuptake inhibitors (25\%) and antipsychotics (19\%). The proportion of patients currently using each class of therapy was numerically higher for the TRD group compared to the non-TRD group, with the exception of SSRIs. The median duration of current treatments was numerically longer for each class of therapy among patients in the TRD versus non-TRD group, with the exception of antiepileptics. 
A.

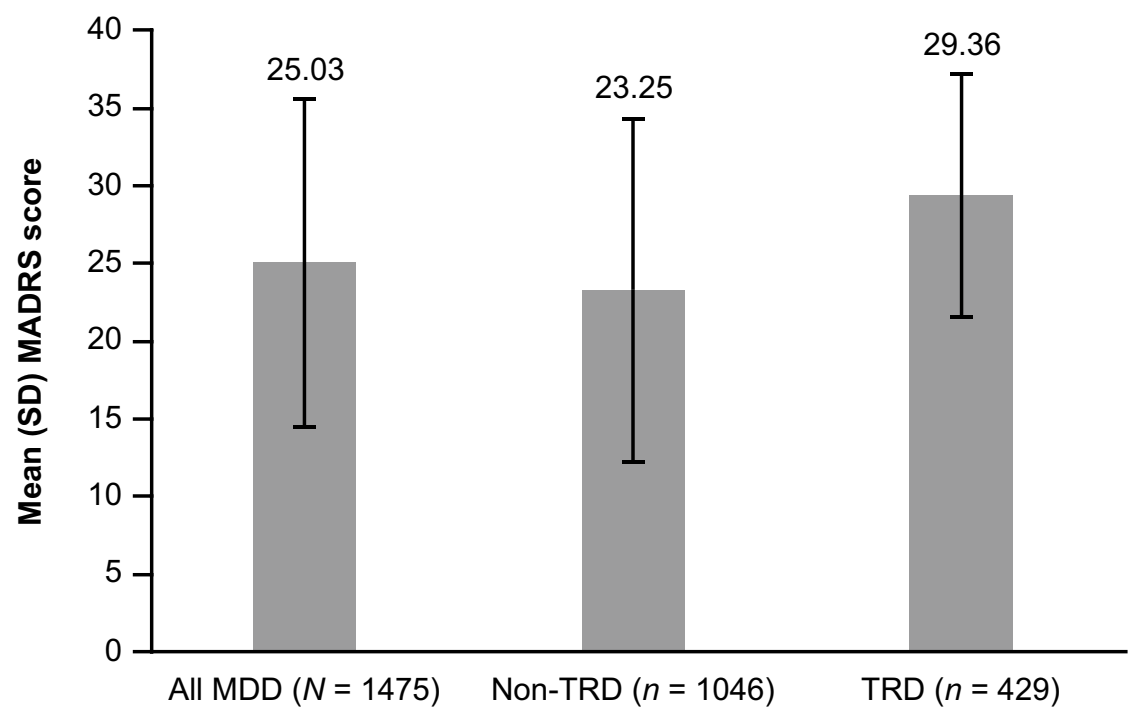

B.

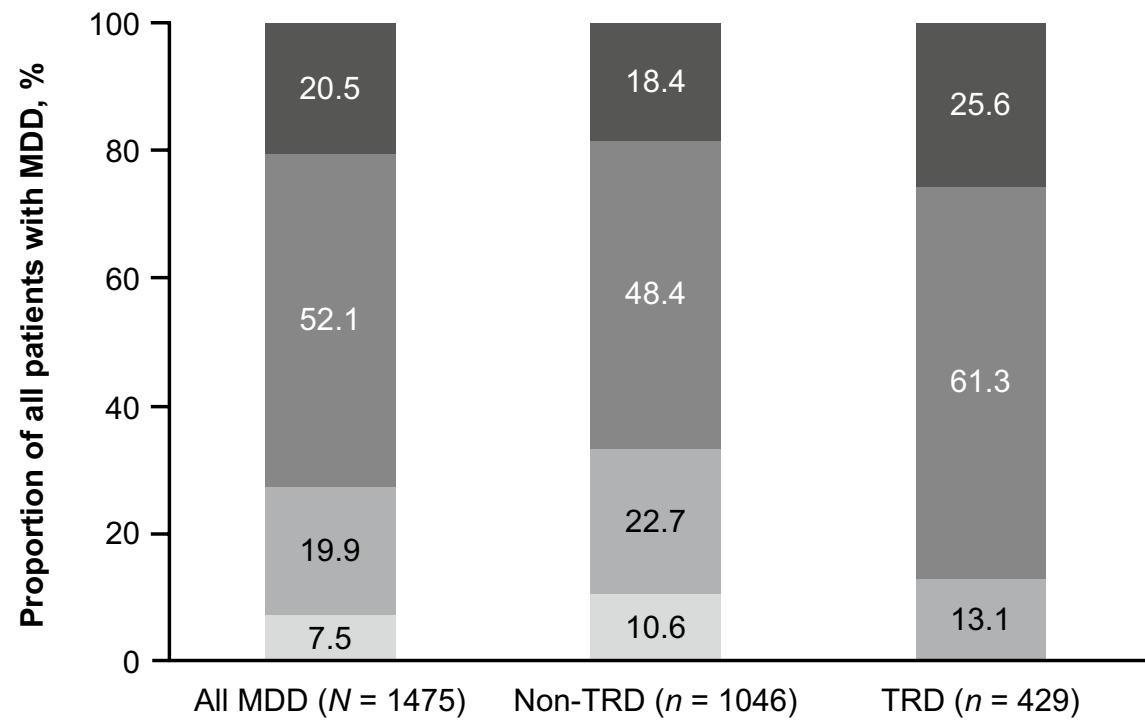

- Severe depression (35-60) Moderate depression (20-34)

Mild depression (7-19)

Symptoms absent (0-6)

Fig. 2 MADRS scores for patients with MDD, non-TRD, and TRD. a Mean (SD) total MADRS score. b Distribution of MADRS scores by severity group.

$M A D R S$ Montgomery-Asberg Depression Rating Scale, MDD major depressive disorder, TRD treatmentresistant depression, $S D$ standard deviation 
Table 4 Selected MINI results

\begin{tabular}{|c|c|c|}
\hline $\begin{array}{l}\text { All MDD } \\
(N=1475)\end{array}$ & $\begin{array}{l}\text { Non-TRD } \\
(n=1046)\end{array}$ & $\begin{array}{l}\text { TRD } \\
(n=429)\end{array}$ \\
\hline
\end{tabular}

Major depressive episode

Meets criteria, $n(\%)$

Current (2 weeks)

Past

Recurrent

$792(53.7 \%)$

$948(90.6 \%)$

$418(97.4 \%)$

$<0.0001$

$761(51.6 \%)$

$533(51.0 \%)$

$259(60.4 \%)$

0.0010

Suicidality

Meets criteria, $n(\%)$

Current (past month)

Lifetime attempt

$449(42.9 \%)$

$312(72.7 \%)$

$<0.0001$

Low

Moderate

High

$358(24.3 \%)$
$265(18.0 \%)$
$195(13.2 \%)$
$67(4.5 \%)$
$216(14.6 \%)$

$207(19.8 \%)$

$151(35.2 \%)$

$<0.0001$

$143(13.7 \%)$

$122(28.4 \%)$

$<0.0001$

$112(10.7 \%)$

$83(19.3 \%)$

$39(3.7 \%)$

$28(6.5 \%)$

$125(12.0 \%)$

$91(21.2 \%)$

Suicide behavior disorder

Meets criteria, $n(\%)$

Current

$96(6.5 \%)$

$59(5.6 \%)$

$37(8.6 \%)$

0.0349

In early remission

$77(5.2 \%)$

$37(3.5 \%)$

$40(9.3 \%)$

$<0.0001$

Panic disorder

Meets criteria, $n(\%)$

Current (past month)

Lifetime

$157(10.6 \%)$
$226(15.3 \%)$

$109(10.4 \%)$

$48(11.2 \%)$

0.6640

Agoraphobia

Meets criteria, $n(\%)$

Current

$136(9.2 \%)$

$64(6.1 \%)$

$72(16.8 \%)$

Social anxiety disorder (social phobia)

Meets criteria, $n(\%)$

Current (past month)

OCD

Meets criteria, $n(\%)$

Current (past month)

PTSD

Meets criteria, $n(\%)$

Current (past month)

$63(4.3 \%)$

$35(3.3 \%)$

$28(6.5 \%)$

0.0061

Alcohol use disorder

Meets criteria, $n(\%)$

Past 12 months

$40(2.7 \%)$

$23(2.2 \%)$

$17(4.0 \%)$

0.0582

Substance use disorder (nonalcohol)

Meets criteria, $n(\%)$

Past 12 months

$15(1.0 \%)$

$6(0.6 \%)$

$9(2.1 \%)$

$0.0175^{\mathrm{b}}$

Anorexia nervosa

Meets criteria, $n(\%)$

Current (past 3 months)

$5(0.3 \%)$

$4(0.4 \%)$

$1(0.2 \%)$

Bulimia nervosa

Meets criteria, $n(\%)$

Current (past 3 months)

$14(0.9 \%)$

$7(0.7 \%)$

$7(1.6 \%)$ 
Table 4 (continued)

$\begin{array}{llll}\text { All MDD } & \text { Non-TRD } & \text { TRD } & P \text { value }^{\mathrm{a}} \\ (N=1475) & (n=1046) & (n=429) & \end{array}$

\begin{tabular}{|c|c|c|c|c|}
\hline \multicolumn{5}{|l|}{ Binge-eating disorder } \\
\hline \multicolumn{5}{|l|}{ Meets criteria, $n(\%)$} \\
\hline Current (past 3 months) & $26(1.8 \%)$ & $18(1.7 \%)$ & $8(1.9 \%)$ & - \\
\hline \multicolumn{5}{|l|}{ Generalized anxiety disorder } \\
\hline \multicolumn{5}{|l|}{ Meets criteria, $n(\%)$} \\
\hline Current (past 6 months) & $298(20.2 \%)$ & $185(17.7 \%)$ & $113(26.3 \%)$ & 0.0002 \\
\hline \multicolumn{5}{|c|}{ Antisocial personality disorder } \\
\hline \multicolumn{5}{|l|}{ Meets criteria, $n(\%)$} \\
\hline Lifetime & $18(1.2 \%)$ & $14(1.3 \%)$ & $4(0.9 \%)$ & 0.5189 \\
\hline
\end{tabular}

MINI Mini International Neuropsychiatric Interview, MDD major depressive disorder, TRD treatmentresistant depression, $O C D$ obsessive compulsive disorder, PTSD posttraumatic stress disorder

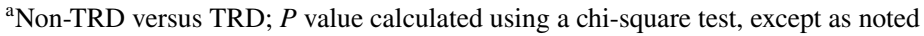

${ }^{\mathrm{b}} P$ value calculated using a Fisher exact test

\section{Healthcare Resource Utilization and Work Productivity}

Overall, 59\% of patients with MDD had received ambulatory care (non-TRD: 57\%; TRD: $66 \%$ ); among these patients, $43 \%$ received up to seven days of care (non-TRD: $54 \%$; TRD: $19 \%$; Table 6). The median number of psychiatric consultations was significantly higher for patients with TRD (5) compared to patients with non-TRD (2). Based on the WPAI:D, in the previous seven days, depression led to a median of $13 \%$ of work time missed, $50 \%$ impairment while working, 58\% overall work impairment, and 60\% activity impairment. Significantly greater impairment was reported for patients with TRD versus non-TRD for the latter three items.

\section{Discussion}

Across four Latin American countries, 29\% of patients with MDD were resistant to treatment, with TRD prevalences of $21 \%$ in Mexico, 32\% in Colombia, 33\% in Argentina, and $40 \%$ in Brazil. In comparison, the STAR*D trial, which enrolled patients with MDD who were candidates for medication as a first treatment step, found that approximately one-third of patients with MDD in the United States were treatment-resistant [5]. Other estimates of TRD in the United States have been lower (7\%-12\%), though, unlike TRAL, diagnosis of MDD and TRD was determined using a retrospective claims database [21, 22]. In Europe, a large multicenter study (European Group for the Study of Resistant Depression) found a TRD prevalence rate of $41 \%$ among patients with MDD, while a UK study of patients being treated for MDD in a primary care setting found that as many as $55 \%$ had TRD [12, 23]. Prevalence rates of TRD in other geographic regions have been estimated at $22 \%$ of patients in Canada receiving antidepressant treatment for MDD from a primary care physician; $21 \%$ of patients in Taiwan with new-onset, pharmaceutically treated MDD; and $12 \%$ of patients in Japan with new-onset, pharmaceutically treated MDD during a 1-year period of time [24-26]. Importantly, definitions 
Table 5 Use of previous and current psychiatric therapies

\begin{tabular}{|c|c|c|c|}
\hline & $\begin{array}{l}\text { All MDD } \\
(N=1475)\end{array}$ & $\begin{array}{l}\text { Non-TRD } \\
(n=1046)\end{array}$ & $\begin{array}{l}\text { TRD } \\
(n=429)\end{array}$ \\
\hline Previous psychiatric medication, $n(\%)$ & $924(62.6 \%)$ & $508(48.6 \%)$ & $416(97.0 \%)$ \\
\hline Other previous relevant medication, $n(\%)$ & $109(7.4 \%)$ & $64(6.1 \%)$ & $45(10.5 \%)$ \\
\hline Current relevant psychiatric therapy, $n(\%)$ & $1318(89.4 \%)$ & $900(86.0 \%)$ & $418(97.4 \%)$ \\
\hline Current other relevant therapy, $n(\%)$ & $551(37.4 \%)$ & $344(32.9 \%)$ & $207(48.3 \%)$ \\
\hline \multicolumn{4}{|l|}{ Duration of current treatments, months } \\
\hline MAOIs, $n(\%)^{\mathrm{a}}$ & $4(0.3 \%)$ & $1(0.1 \%)$ & $3(0.7 \%)$ \\
\hline Median & 17.00 & 14.00 & 20.00 \\
\hline Minimum & 0.00 & 14.00 & 0.00 \\
\hline Maximum & 21.00 & 14.00 & 21.00 \\
\hline Missing ${ }^{\mathrm{b}}$ & 0 & 0 & 0 \\
\hline Tricyclic antidepressants, $n(\%)^{\mathrm{a}}$ & $29(2.1 \%)$ & $11(1.2 \%)$ & $18(4.3 \%)$ \\
\hline Median & 7.50 & 4.00 & 10.00 \\
\hline Minimum & 0.00 & 0.00 & 1.00 \\
\hline Maximum & 122.00 & 122.00 & 75.00 \\
\hline Missing ${ }^{\mathrm{b}}$ & 1 & 0 & 1 \\
\hline SSRIs, $n(\%)^{\mathrm{a}}$ & $843(62.4 \%)$ & $617(66.4 \%)$ & $226(53.6 \%)$ \\
\hline Median & 2.00 & 1.00 & 4.00 \\
\hline Minimum & 0.00 & 0.00 & 0.00 \\
\hline Maximum & 218.00 & 218.00 & 217.00 \\
\hline Missing ${ }^{\mathrm{b}}$ & 28 & 17 & 11 \\
\hline SNRIs, $n(\%)^{\mathrm{a}}$ & $335(24.8 \%)$ & $195(21.0 \%)$ & $140(33.2 \%)$ \\
\hline Median & 2.00 & 2.00 & 3.00 \\
\hline Minimum & 0.00 & 0.00 & 0.00 \\
\hline Maximum & 203.00 & 203.00 & 140.00 \\
\hline Missing ${ }^{\mathrm{b}}$ & 16 & 7 & 9 \\
\hline SDRIs, $n(\%)^{\mathrm{a}}$ & $49(3.6 \%)$ & $19(2.0 \%)$ & $30(7.1 \%)$ \\
\hline Median & 7.00 & 7.00 & 7.50 \\
\hline Minimum & 0.00 & 0.00 & 0.00 \\
\hline Maximum & 74.00 & 74.00 & 63.00 \\
\hline Missing $^{\mathrm{b}}$ & 4 & 0 & 4 \\
\hline Multimodal, $n(\%)^{\mathrm{a}}$ & $39(2.9 \%)$ & $19(2.0 \%)$ & $20(4.7 \%)$ \\
\hline Median & 3.00 & 1.00 & 3.00 \\
\hline Minimum & 0.00 & 0.00 & 0.00 \\
\hline Maximum & 25.00 & 25.00 & 12.00 \\
\hline Missing $^{\mathrm{b}}$ & 0 & 0 & 0 \\
\hline Antipsychotics, $n(\%)^{\mathrm{a}}$ & $261(19.3 \%)$ & $128(13.8 \%)$ & $133(31.5 \%)$ \\
\hline Median & 2.00 & 1.00 & 3.00 \\
\hline Minimum & 0.00 & 0.00 & 0.00 \\
\hline Maximum & 105.00 & 72.00 & 105.00 \\
\hline Missing $^{\mathrm{b}}$ & 21 & 7 & 14 \\
\hline Antiepileptics, $n(\%)^{\mathrm{a}}$ & $133(9.8 \%)$ & $71(7.6 \%)$ & $62(14.7 \%)$ \\
\hline Median & 10.00 & 11.00 & 9.50 \\
\hline Minimum & 0.00 & 0.00 & 0.00 \\
\hline Maximum & 355.00 & 302.00 & 355.00 \\
\hline Missing $^{\mathrm{b}}$ & 14 & 8 & 6 \\
\hline
\end{tabular}


Table 5 (continued)

\begin{tabular}{|c|c|c|c|}
\hline & $\begin{array}{l}\text { All MDD } \\
(N=1475)\end{array}$ & $\begin{array}{l}\text { Non-TRD } \\
(n=1046)\end{array}$ & $\begin{array}{l}\text { TRD } \\
(n=429)\end{array}$ \\
\hline Brain stimulation techniques, $n(\%)^{\mathrm{a}}$ & $2(0.1 \%)$ & $0(0.0 \%)$ & $2(0.5 \%)$ \\
\hline Median & 3.00 & - & 3.00 \\
\hline Minimum & 1.00 & - & 1.00 \\
\hline Maximum & 5.00 & - & 5.00 \\
\hline Missing ${ }^{\mathrm{b}}$ & 0 & 0 & 0 \\
\hline Psychotherapy, $n(\%)^{\mathrm{a}}$ & $5(0.4 \%)$ & $1(0.1 \%)$ & $4(0.9 \%)$ \\
\hline Median & 3.00 & - & 3.00 \\
\hline Minimum & 1.00 & - & 1.00 \\
\hline Maximum & 5.00 & - & 5.00 \\
\hline Missing ${ }^{\mathrm{b}}$ & 2 & 0 & 2 \\
\hline Others, $n(\%)^{\mathrm{a}}$ & $12(0.9 \%)$ & $4(0.4 \%)$ & $8(1.9 \%)$ \\
\hline Median & 0.50 & 0.50 & 0.50 \\
\hline Minimum & 0.00 & 0.00 & 0.00 \\
\hline Maximum & 47.00 & 1.00 & 47.00 \\
\hline Missing $^{\mathrm{b}}$ & 0 & 0 & 0 \\
\hline Current use of ketamine/esketamine, $n(\%)^{\mathrm{a}}$ & $1(0.1 \%)$ & $0(0.0 \%)$ & $1(0.2 \%)$ \\
\hline Previous use of ketamine/esketamine, $n(\%)^{\mathrm{c}}$ & $9(1.0 \%)$ & $0(0.0 \%)$ & $9(2.2 \%)$ \\
\hline Current use of lithium, $n(\%)^{\mathrm{a}}$ & $50(3.7 \%)$ & $11(1.2 \%)$ & $39(9.2 \%)$ \\
\hline Previous use of lithium, $n(\%)^{\mathrm{c}}$ & $47(5.0 \%)$ & $10(1.9 \%)$ & $37(8.9 \%)$ \\
\hline
\end{tabular}

$M D D$ major depressive disorder, TRD treatment-resistant depression, $M A O I$ monoamine oxidase inhibitor, $S S R I$ selective serotonin reuptake inhibitor, SNRI serotonin and noradrenaline reuptake inhibitor, SDRI serotonin and dopamine reuptake inhibitor

${ }^{\text {a }}$ Percentages were calculated using the total number of patients using current relevant psychiatric therapy or current other relevant therapy (1351 patients among all patients with MDD)

${ }^{b}$ Number of patients who were missing data for the calculation of treatment duration

${ }^{\mathrm{c}}$ Percentages were calculated using the total number of patients with data for previous use of ketamine/ esketamine and/or lithium (935 patients among all patients with MDD)

of TRD varied across these studies, limiting direct comparison. The variation in TRD prevalence by country is further discussed below, but it is notable that there may be greater reluctance to report and seek treatment for depression and, by extension, TRD, among patients in East Asian countries.

In this interim analysis of TRAL, while the prevalence of TRD was similar in private and public sites of care overall, numerical differences were observed in some countries. In Colombia, $35 \%$ of patients in private settings had TRD versus $24 \%$ of patients in public settings; in contrast, in Brazil, $17 \%$ of patients in private settings had TRD versus $45 \%$ of patients in public settings. The higher prevalence of TRD in Brazilian public settings could be due to the nature of these public services, most of which are university-based research centers, with a greater demand from higher-complexity and more severe patients; however, further information is needed to confirm this assumption. When sites of care were examined in more detail among all patients with MDD, the site with the highest prevalence of TRD was the general hospital setting (60\%). Notably, variability in access to healthcare may limit comparisons across countries. Variability in the types of care settings that participated in the current study may also limit interpretation of these results. 
Table 6 Healthcare resource utilization and work productivity

\begin{tabular}{|c|c|c|c|c|}
\hline & $\begin{array}{l}\text { All MDD } \\
(N=1475)\end{array}$ & $\begin{array}{l}\text { Non-TRD } \\
(n=1046)\end{array}$ & $\begin{array}{l}\text { TRD } \\
(n=429)\end{array}$ & $P$ value $^{\mathrm{a}}$ \\
\hline Ambulatory care, $n(\%)$ & $877(59.5 \%)$ & $594(56.8 \%)$ & $283(66.0 \%)$ & \\
\hline \multicolumn{5}{|l|}{ Number of days, $n(\%)^{\mathrm{b}}$} \\
\hline$\leq 7$ & $375(42.9 \%)$ & $321(54.1 \%)$ & $54(19.1 \%)$ & \\
\hline$>7$ to $\leq 30$ & $280(32.0 \%)$ & $166(28.0 \%)$ & $114(40.4 \%)$ & \\
\hline$>30$ to $\leq 60$ & $58(6.6 \%)$ & $31(5.2 \%)$ & $27(9.6 \%)$ & \\
\hline$>60$ to $\leq 90$ & $143(16.3 \%)$ & $66(11.1 \%)$ & $77(27.3 \%)$ & \\
\hline$>90$ & $19(2.2 \%)$ & $9(1.5 \%)$ & $10(3.5 \%)$ & \\
\hline Number of ED visits, $n$ & 826 & 563 & 263 & \\
\hline Median & 0.00 & 0.00 & 0.00 & \\
\hline Minimum & 0.00 & 0.00 & 0.00 & \\
\hline Maximum & 30.00 & 30.00 & 20.00 & \\
\hline Number of psychiatrist consultations, $n$ & 863 & 587 & 276 & $<0.0001$ \\
\hline Median & 2.00 & 2.00 & 5.00 & \\
\hline Minimum & 0.00 & 0.00 & 0.00 & \\
\hline Maximum & 64.00 & 60.00 & 64.00 & \\
\hline Number of psychologist consultations, $n$ & 819 & 561 & 258 & \\
\hline Median & 0.00 & 0.00 & 0.00 & \\
\hline Minimum & 0.00 & 0.00 & 0.00 & \\
\hline Maximum & 55.00 & 50.00 & 55.00 & \\
\hline Number of other specialist consultations, $n$ & 807 & 551 & 256 & \\
\hline Median & 0.00 & 0.00 & 0.00 & \\
\hline Minimum & 0.00 & 0.00 & 0.00 & \\
\hline Maximum & 72.00 & 30.00 & 72.00 & \\
\hline Number of primary care physician consultations, $n$ & 806 & 553 & 253 & \\
\hline Median & 0.00 & 0.00 & 0.00 & \\
\hline Minimum & 0.00 & 0.00 & 0.00 & \\
\hline Maximum & 24.00 & 24.00 & 24.00 & \\
\hline Number of other health professional consultations, $n$ & 803 & 551 & 252 & \\
\hline Median & 0.00 & 0.00 & 0.00 & \\
\hline Minimum & 0.00 & 0.00 & 0.00 & \\
\hline Maximum & 44.00 & 28.00 & 44.00 & \\
\hline $\begin{array}{l}\text { Number of nonpharmaceutical treatment consulta- } \\
\quad \text { tions, } n\end{array}$ & 800 & 550 & 250 & \\
\hline Median & 0.00 & 0.00 & 0.00 & \\
\hline Minimum & 0.00 & 0.00 & 0.00 & \\
\hline Maximum & 14.00 & 3.00 & 14.00 & \\
\hline \multicolumn{5}{|l|}{ WPAI:D } \\
\hline Percent work time missed due to depression, $n$ & 596 & 459 & 137 & 0.3813 \\
\hline Median & 12.77 & 11.11 & 17.65 & \\
\hline Minimum & 0.00 & 0.00 & 0.00 & \\
\hline Maximum & 100.00 & 100.00 & 100.00 & \\
\hline Percent impairment while working due to depression, $n$ & 529 & 407 & 122 & 0.0036 \\
\hline Median & 50.00 & 50.00 & 60.00 & \\
\hline Minimum & 0.00 & 0.00 & 0.00 & \\
\hline Maximum & 100.00 & 100.00 & 100.00 & \\
\hline
\end{tabular}


Table 6 (continued)

\begin{tabular}{|c|c|c|c|c|}
\hline & $\begin{array}{l}\text { All MDD } \\
(N=1475)\end{array}$ & $\begin{array}{l}\text { Non-TRD } \\
(n=1046)\end{array}$ & $\begin{array}{l}\text { TRD } \\
(n=429)\end{array}$ & $P$ value $^{\mathrm{a}}$ \\
\hline Percent overall work impairment due to depression, $n$ & 528 & 407 & 121 & \\
\hline Median & 58.17 & 55.00 & 64.00 & 0.0025 \\
\hline Minimum & 0.00 & 0.00 & 0.00 & \\
\hline Maximum & 100.00 & 100.00 & 100.00 & \\
\hline Percent activity impairment due to depression, $n$ & 1473 & 1045 & 428 & \\
\hline Median & 60.00 & 50.00 & 70.00 & $<0.0001$ \\
\hline Minimum & 0.00 & 0.00 & 0.00 & \\
\hline Maximum & 100.00 & 100.00 & 100.00 & \\
\hline
\end{tabular}

$M D D$ major depressive disorder, TRD treatment-resistant depression, ED emergency department, WPAI:D Work Productivity and Activity Impairment Questionnaire: Depression

${ }^{a}$ Non-TRD versus TRD; $P$ value calculated using a Mann-Whitney nonparametric test

${ }^{\mathrm{b}}$ Two patients had missing data (one non-TRD and one TRD)

This interim analysis identified several concerning demographic characteristics of patients in Latin American with MDD. The mean age at which MDD was diagnosed was 37.9 years overall, 38.2 years for patients with non-TRD, and 37.3 years for patients with TRD, suggesting that earlier diagnosis of MDD in Latin American countries is important. Earlier diagnosis could lead to earlier treatment, better outcomes for patients, and potentially a decreased burden of disease for patients and caregivers [27]. Additionally, more women than men were diagnosed with MDD. This is consistent with global reports of depression prevalence that have demonstrated that female sex is a significant risk factor for depression [28].

Previous studies have found higher hospitalization rates and lengths of stay for patients with TRD compared to those with non-TRD [9, 13]; however, no such associations were observed in the interim analysis of the current study. This finding may reflect economic and cultural differences between Latin America and higher-income countries. In Latin America, patients with MDD may face external challenges accessing mental healthcare, as well as stigma associated with seeking care for mental health. Moreover, it is important to note that the current analysis includes only data from the baseline study visit, and hospitalization information was taken retrospectively. Healthcare resource utilization will also be evaluated in the 1-year longitudinal phase of TRAL; follow-up during this phase will include direct collection of hospitalization information and thus may provide more accurate information than that collected in Phase 1.

A higher mean MADRS total score was observed in the TRD group (29.4; SD: 7.9) than in the non-TRD group (23.3; SD: 11.2). Among patients with TRD, $87 \%$ had moderate or severe depression; however, the relatively high proportion of patients with TRD who were classified as having moderate depression (61\%) compared to severe depression (26\%) was surprising. This indicates that the greatest proportion of unmet need for patients in Latin America with TRD may be in treatment of moderate depression.

Based on current disease status items and the MINI, numerous factors were significantly more common among patients with TRD versus non-TRD, including suicidality and anxiety. This is in agreement with other published data; a large European multicenter 
study showed an association between suicidality and treatment resistance [12], and other studies have demonstrated associations between TRD and comorbid anxiety disorders [29, 30]. A systematic review of socio-demographic and clinical predictors of TRD found that a current or lifetime diagnosis of generalized anxiety disorder was predictive of nonresponse to depression treatment, while anxious symptoms, irrespective of a diagnosis, influenced remission from depression [28]. Further, the presence of more than 1 anxiety disorder in a single patient is also associated with TRD [29].

Compared to patients with non-TRD, numerically higher proportions of those with TRD had taken a previous psychiatric medication or were currently receiving relevant psychiatric therapy. Use of numerous classes of treatment were observed among patients with TRD, although therapies such as brain stimulation techniques (1\%) and ketamine/ esketamine ( $<1 \%$ current use; $2 \%$ previous use) were low, potentially due to difficulty accessing them. Notably, for some treatment classes, many patients had missing data (the exact number varied by treatment class). This is likely due to patients not remembering previous treatments or the correct dates or doses of previous treatment regimens.

While TRD has been associated with increased healthcare resource utilization [9, 31], the only significant difference observed in the current study was a higher number of psychiatrist consultations for patients with TRD in comparison to non-TRD. As discussed previously, this may be due, at least in part, to difficulty of access and cultural sensitivities around seeking help for mental health issues in Latin America. As expected based on previous studies $[9,10]$, patients with TRD demonstrated significantly greater work impairment than patients with non-TRD on most WPAI:D items.

One of the strengths of this study is the quality of the diagnosis of MDD, which was defined, in part, using the semi-structured interview, MINI. Many TRD studies have defined MDD using presumptive diagnoses from patient registry databases of public or private health services. This more direct MDD diagnosis ensures a more uniform study population and thus the potential to detect more subtle differences between groups. Importantly, the present analysis represents baseline results; further information will be reported upon study completion.

The present study is not a population-based survey, as it included only individuals being assisted in clinical services (clinics, hospitals, community services) that treat mental disorders, independent of whether they are specialized or not. This could be perceived as a limitation for a prevalence study, considering that many cases of depression go undiagnosed in a general medicine setting. However, it was the authors' decision to investigate the prevalence of treatment resistance among those diagnosed with MDD and to investigate predictors of TRD and differences between TRD and non-TRD populations.

\section{Conclusion}

Present findings demonstrate that TRD represents a disproportional economic and social burden to healthcare systems, patients, and their families, and continues to be a substantial unmet need in the treatment of depression, including in Latin America.

Supplementary Information The online version contains supplementary material available at https://doi. org/10.1007/s11126-021-09930-x. 
Acknowledgements We, the authors, dedicate this paper to our co-author, Dr. Rodrigo Pérez-Esparza, who recently passed away. Dr. Pérez-Esparza was a major contributor to this work, not only as a study investigator and author of this manuscript, but also as a tireless participant in the design and protocol development of the TRAL study. We extend our greatest sympathy to Dr. Pérez-Esparza's family and friends. Dr. PérezEsparza was supported by Consejo Nacional de Ciencia y Tecnología, Mexico (CONACyT) and CONACyT's Sistema Nacional de Investigadores. The authors also thank the study patients and the investigators for their participation in this study. Medical writing support was provided by Courtney St. Amour, PhD, of Cello Health Communications/MedErgy (Yardley, PA, USA) and was funded by Janssen Pharmaceutical Companies of Johnson \& Johnson.

Authors' Contributions Bernardo Soares and Rodrigo Pérez-Esparza contributed to study conception and design. Chei Tung Teng, Rodrigo Pérez-Esparza, Gerardo Garcia Bonetto, Acioly L.T. Lacerda, Erasmo Saucedo Uribe, Rodrigo Cordoba, Christian Lupo, and Aline Medeiros Samora contributed to data acquisition. Aline Medeiros Samora and Patricia Cabrera contributed to data analysis. Bernardo Soares, Gabriela Kanevsky, Chei Tung Teng, Erasmo Saucedo Uribe, and Patricia Cabrera contributed to data interpretation. All authors contributed to drafting and/or critical review of the manuscript and approved the final version for publication.

Funding This study was sponsored by Janssen Pharmaceutical Companies of Johnson \& Johnson, from study design, conduction, monitoring, and database analysis to medical writing of the manuscript and its submission for publication.

Availability of Data and Material The data sharing policy of Janssen Pharmaceutical Companies of Johnson \& Johnson is available at https://www.janssen.com/clinical-trials/transparency. As noted on this site, requests for access to the study data can be submitted through the Yale Open Data Access (YODA) Project site at http://yoda.yale.edu.

\section{Declarations}

Ethics Approval This study was conducted in accordance with local institutional ethics committees or institutional review boards (see Online Resource 1 for a listing), the values of the Declaration of Helsinki, the current guidelines of the International Conference of Harmonization and Good Clinical Practice, applicable regulatory requirements, and the sponsor's policy.

Consent to Participate All participants provided informed consent via a form approved by local institutional ethics committees or institutional review boards (see Online Resource 1 for a listing).

Competing Interests Bernardo Soares and Patricia Cabrera were employees of Janssen-Cilag at the time of their work on this study; Bernardo Soares is currently affiliated with Sanofi - Brazil, and Patricia Cabrera is currently affiliated with Janssen Global Services, Inc. Gabriela Kanevsky and Aline Medeiros Samora are employees of Janssen-Cilag. Chei Tung Teng has consulted or served on an advisory board for Janssen Cilag Farmaceutica, Lundbeck do Brasil, Servier do Brasil, Abbott Laboratórios do Brasil, Medley Farmaceutica, Takeda Distribuidora, SEM, and Torrent do Brasil, and has received grant or research support from Abbott Laboratórios do Brasil, Libbs Farmaceutica, Lundbeck do Brasil, Medley Farmaceutica, Ache Laboratorios Farmaceuticos, Torrent do Brasil, Biolab Sanus Farmaceutica, Laboratorios Pfizer, Servier do Brasil, and Apsen Farmaceutica, and EMS. Rodrigo Pérez-Esparza and Rodrigo Cordoba report no conflicts of interest. Gerardo Garcia Bonetto has performed clinical research for Roche, Janssen, Eisay, Otsuka, Lumbek, and Pfizer. Acioly L.T. Lacerda has received consulting fees from Hoffmann-La Roche, Genentech, Janssen Pharmaceutical, Daiichi Sankyo, Cristalia Produtos Químicos e Farmacêuticos, Pfizer, Mantecorp Indústria Química e Farmacêutica, Libbs Farmacêutica, FQM Farma, and Sanofi-Aventis over the last 24 months and has received research fees from Janssen Pharmaceutical, Eli Lilly, Novartis, Biophytis, Celltrion, Azidus, H. Lundbeck A/S, Servier Laboratories, Hoffman-La Roche, FQM Farma, and Forum Pharmaceuticals. Erasmo Saucedo Uribe has served as a consultant for Janssen-Cilag. Christian Lupo has performed clinical research for Janssen Pharmaceuticals, Novartis, Eli Lilly, Lundbeck, Servier, AstraZeneca, Bago, Wyeth, Pfizer, Otsuka, Takeda, and Sunovion, and has served as a speaker for Eli Lilly, Servier, Lundbeck, Chobet, and Janssen Pharmaceuticals.

Open Access This article is licensed under a Creative Commons Attribution 4.0 International License, which permits use, sharing, adaptation, distribution and reproduction in any medium or format, as long 
as you give appropriate credit to the original author(s) and the source, provide a link to the Creative Commons licence, and indicate if changes were made. The images or other third party material in this article are included in the article's Creative Commons licence, unless indicated otherwise in a credit line to the material. If material is not included in the article's Creative Commons licence and your intended use is not permitted by statutory regulation or exceeds the permitted use, you will need to obtain permission directly from the copyright holder. To view a copy of this licence, visit http://creativecommons.org/licenses/by/4.0/.

\section{References}

1. World Health Organization. Depression and other common mental disorders: global health estimates. Geneva, Switzerland: WHO Document Production Services; 2017.

2. American Psychiatric Association. Diagnostic and statistical manual of mental disorders. 5th ed. Arlington, VA: American Psychiatric Association; 2013.

3. Wang J, Wu X, Lai W, Long E, Zhang X, Li W, et al. Prevalence of depression and depressive symptoms among outpatients: a systematic review and meta-analysis. BMJ Open. 2017;7:e017173.

4. de Sousa RT, Zanetti MV, Brunoni AR, Machado-Vieira R. Challenging treatment-resistant major depressive disorder: a roadmap for improved therapeutics. Curr Neuropharmacol. 2015;13:616-35.

5. Rush AJ, Trivedi MH, Wisniewski SR, Nierenberg AA, Stewart JW, Warden D, et al. Acute and longer-term outcomes in depressed outpatients requiring one or several treatment steps: a STAR*D report. Am J Psychiatry. 2006;163:1905-17.

6. Gaynes BN, Asher G, Gartlehner G, Hoffman V, Green J, Boland E, et al. Definition of treatment-resistant depression in the Medicare population. Technology assessment program. Project ID: PSYT0816. (Prepared by RTI-UNC Evidence-Based Practice Center under Contract No. HSA290201500011I_HHSA29032006T). Rockville, MD: Agency for Healthcare Research and Quality. 2018. https://www.cms.gov/Medicare/Coverage/ DeterminationProcess/downloads/id105TA.pdf. Accessed 9 April 2019.

7. Conway CR, George MS, Sackeim HA. Toward an evidence-based, operational definition of treatmentresistant depression: when enough is enough. JAMA Psychiat. 2017;74:9-10.

8. Kubitz N, Mehra M, Potluri RC, Garg N, Cossrow N. Characterization of treatment resistant depression episodes in a cohort of patients from a US commercial claims database. PLoS One. 2013;8:e76882.

9. Amos T, Tandon N, Lefebvre P, Pilon D, Kamstra RL, Pivneva I, et al. Direct and indirect cost burden and change of employment status in treatment-resistant depression: a matched-cohort study using a US commercial claims database. J Clin Psychiatry. 2018;79:17m11725.

10. DiBernardo A, Lin X, Zhang Q, Xiang J, Lu L, Jamieson C, et al. Humanistic outcomes in treatment resistant depression: a secondary analysis of the STAR*D study. BMC Psychiatry. 2018;18:352.

11. Mrazek DA, Hornberger JC, Altar CA, Degtiar I. A review of the clinical, economic, and societal burden of treatment-resistant depression: 1996-2013. Psychiatr Serv. 2014;65:977-87.

12. Dold M, Bartova L, Fugger G, Kautzky A, Souery D, Mendlewicz J, et al. Major depression and the degree of suicidality: results of the European Group for the Study of Resistant Depression (GSRD). Int J Neuropsychopharmacol. 2018;21:539-49.

13. Pilon D, Sheehan JJ, Szukis H, Singer D, Jacques P, Lejeune D, et al. Medicaid spending burden among beneficiaries with treatment-resistant depression. J Comp Eff Res. 2019;8:381-92.

14. Johnston KM, Powell LC, Anderson IM, Szabo S, Cline S. The burden of treatment-resistant depression: a systematic review of the economic and quality of life literature. $\mathrm{J}$ Affect Disord. 2019;242:195-210.

15. Ionescu DF, Rosenbaum JF, Alpert JE. Pharmacological approaches to the challenge of treatmentresistant depression. Dialogues Clin Neurosci. 2015;17:111-26.

16. SPRAVATO ${ }^{\mathrm{TM}}$ (esketamine) nasal spray [package insert]. Lakewood, NJ: Renaissance Lakewood LLC; 2019.

17. SYMBYAX (olanzapine and fluoxetine hydrochloride) capsule for oral use [package insert]. Indianapolis, IN: Eli Lilly and Company; 2009.

18. Castilla-Puentes RC, Secin R, Grau A, Galeno R, Feijo de Mello M, Pena N, et al. A multicenter study of major depressive disorder among emergency department patients in Latin-American countries. Depress Anxiety. 2008;25:E199-E204.

19. Muñoz RA, McBride ME, Brnabic AJ, López CJ, Hetem LA, Secin R, et al. Major depressive disorder in Latin America: the relationship between depression severity, painful somatic symptoms, and quality of life. J Affect Disord. 2005;86:93-8. 
20. Huang H, Menezes PR, da Silva SA, Tabb K, Barkil-Oteo A, Scazufca M. The association between depressive disorders and health care utilization: results from the São Paulo Ageing and Health study (SPAH). Gen Hosp Psychiatry. 2014;36:199-202.

21. Pilon D, Szukis H, Singer D, Sheehan JJ, Wu JW, Lefebvre P, et al. Cost burden of patients with treatmentresistant depression who received care in US integrated delivery networks: a retrospective claims database analysis. Poster presented at: Academy of Managed Care Pharmacy (AMCP) Nexus Meeting; 22-25 Oct 2018; Orlando, FL.

22. Pilon D, Joshi K, Sheehan JJ, Zichlin ML, Zuckerman P, Lefebvre P, et al. Burden of treatment-resistant depression in Medicare: a retrospective claims database analysis. PLoS One. 2019;14:e0223255.

23. Thomas L, Kessler D, Campbell J, Morrison J, Peters TJ, Williams C, et al. Prevalence of treatmentresistant depression in primary care: cross-sectional data. Br J Gen Pract. 2013;63:e852-8.

24. Rizvi SJ, Grima E, Tan M, Rotzinger S, Lin P, McIntyre RS, et al. Treatment-resistant depression in primary care across Canada. Can J Psychiatry. 2014;59:349-57.

25. Fife D, Feng Y, Wang MY, Chang CJ, Liu CY, Juang HT, et al. Epidemiology of pharmaceutically treated depression and treatment resistant depression in Taiwan. Psychiatry Res. 2017;252:277-83.

26. Mahlich J, Tsukazawa S, Wiegand F. Estimating prevalence and healthcare utilization for treatmentresistant depression in Japan: a retrospective claims database study. Drugs Real World Outcomes. 2018;5:35-43.

27. Kraus C, Kadriu B, Lanzenberger R, Zarate CA Jr, Kasper S. Prognosis and improved outcomes in major depression: a review. Transl Psychiatry. 2019;9:127.

28. Gutiérrez-Rojas L, Porras-Segovia A, Dunne H, Andrade-González N, Cervilla JA. Prevalence and correlates of major depressive disorder: a systematic review. Braz J Psychiatry. 2020;42:657-72.

29. De Carlo V, Calati R, Serretti A. Socio-demographic and clinical predictors of non-response/ non-remission in treatment resistant depressed patients: a systematic review. Psychiatry Res. 2016;240:421-30.

30. Mogi T, Yoshino A. The multiple diagnoses of comorbid anxiety disorders and higher interpersonal sensitivity predict treatment-resistant depression. Asian J Psychiatr. 2017;26:131-5.

31. Pilon D, Amos TB, Germain G, Lafeuille MH, Lefebvre P, Benson CJ. Treatment persistence and hospitalization rates among patients with schizophrenia: a quasi-experiment to evaluate a patient information program. Curr Med Res Opin. 2017;33:713-21.

Publisher's Note Springer Nature remains neutral with regard to jurisdictional claims in published maps and institutional affiliations.

Bernardo Soares is a psychiatrist dedicated to care in clinical psychiatry and pharmaceutical industry roles, with over 15 years of experience. He is currently Medical Director at Sanofi Genzyme.

Gabriela Kanevsky is a pediatrician with over 12 years of experience in the pharmaceutical industry. Her current position is Senior Regional Medical Manager, Neurosciences, at Janssen Pharmaceuticals.

Chei Tung Teng is a psychiatrist and Professor of Psychiatry at the Institute of Psychiatry, University of São Paulo School of Medicine Clinics Hospital, of São Paulo.

Rodrigo Pérez-Esparza was a neuropsychiatrist and clinical researcher at Instituto Nacional de Neurologia y Neurocirugía.

Gerardo Garcia Bonetto is a psychiatrist dedicated to care in psychiatry and research at Hospital Neuropsiquiatrico, Córdoba.

Acioly L.T. Lacerda is a psychiatrist and Executive Director at BR Trials. He is dedicated to care in clinical psychiatry and neuropsychiatry, in addition to working in the areas of teaching and research at Universidade Federal de São Paulo.

Erasmo Saucedo Uribe is a psychiatrist with over 20 years of experience managing patients with emotional disorders. He is an investigator and Profesor at Hospital Universitario, Universidad Autónoma de Nuevo León, Monterrey.

Rodrigo Cordoba is a psychiatrist, professor, and researcher at Universidad del Rosario, Bogotá. 
Christian Lupo is a psychiatrist and Director at Centro de Investigación y Asistencia en Psiquiatría.

Aline Medeiros Samora has a PhD in epidemiology and more than 7 years of experience managing clinical trials.

Patricia Cabrera is a specialist in epidemiology. She has over 15 years of experience in the pharmaceutical industry and is currently Global Medical Affairs Director, Neurosciences, at Janssen Global Services, Inc.

\section{Authors and Affiliations}

\section{Bernardo Soares ${ }^{1} \cdot$ Gabriela Kanevsky $^{2} \cdot$ Chei Tung Teng $^{3} \cdot$ Rodrigo Pérez-Esparza $^{4}$. Gerardo Garcia Bonetto ${ }^{5}$ Acioly L. T. Lacerda ${ }^{6}$. Erasmo Saucedo Uribe ${ }^{7}$. Rodrigo Cordoba ${ }^{8} \cdot$ Christian Lupo $^{9} \cdot$ Aline Medeiros Samora ${ }^{10} \cdot$ Patricia Cabrera $^{11}$}

1 Janssen Cilag-United Kingdom, Buckinghamshire, UK

2 Janssen Cilag-Argentina, Buenos Aires, Argentina

3 Department of Psychiatry, Institute of Psychiatry, University of São Paulo School of Medicine Clinics Hospital, São Paulo, Brazil

4 Addiction Research Laboratory, Instituto Nacional de Neurologia y Neurocirugía, Mexico City, Mexico

5 Investigaciones Clinicas-Instituto Medico DAMIC, Hospital Neuropsiquiatrico, Córdoba, Argentina

6 PRODAF - Programa de Transtornos Afetivos and Laboratory of Integrative Neuroscience, Universidade Federal de São Paulo; and CNS Unit, BR Trials, São Paulo, Brazil

7 Departamento de Psiquiatria, Centro de Neurociencias Avanzadas, Hospital Universitario, Universidad Autónoma de Nuevo León, Monterrey, Nuevo León, México

8 Escuela de Medicina y Ciencias de la Salud, Universidad del Rosario; Centro Rosarista de Salud Mental; and Centro de Investigaciones del Sistema Nervioso - Grupo Cisne, Bogotá, Colombia

9 Centro de Investigación y Asistencia en Psiquiatría, Rosario and National University of Rosario, Santa Fe, Argentina

10 Janssen Cilag-Brazil, São Paulo, Brazil

11 Janssen Cilag-Colombia, Bogotá, Colombia 